\title{
TRAINING OF POSTGRADUATE STUDENTS IN PATHOLOGY, CURRENT SCENARIO AND HOW IT CAN BE IMPROVED: A REVIEW
}

Prasad Uma ${ }^{1}$

\section{HOW TO CITE THIS ARTICLE:}

Prasad Uma. "Training of Postgraduate Students in Pathology, Current Scenario and how it can be improved: A Review". Journal of Evolution of Medical and Dental Sciences 2015; Vol. 4, Issue 40, May 18; Page: 7064-7070, DOI: $10.14260 /$ jemds/2015/1026

ABSTRACT: There a wide variation in the competence of the postgraduates trained in pathology across the country. The curriculum and training methods vary from Government Medical Colleges to Autonomous Institutes. This results in strong disparities in the diagnostic, teaching, research and the managerial skills of the graduates. A uniform and better trained pathologist would be a great asset to the society. The Government Medical Colleges have the hub of budding pathologists, a proper curriculum planning and emphasis on learning of recent techniques with proper career planning would help pathology practice in a long way. In this article an effort was made to compile the various views of eminent educationists in the field of medicine, the current scenario and the methods needed to rectify at our level.

KEYWORDS: Training, Pathology postgraduates, Current scenario, Rectification.

INTRODUCTION: The past century has seen tremendous changes in the scope and practice of pathology laboratories in tandem with the development of the medical services. Major progress was made in the areas of training and specialization of pathologists and laboratory technical staff. Today the pathology laboratory services have entered the International arena, and are propelled along the wave of globalization. Many new challenges have emerged as have new players in the field. Landmark developments over the past decade include the establishment of national quality assurance programmers, the mushrooming of private pathology laboratories, the establishment of a National Accreditation Standard for medical testing laboratories. There exists a wide variation in the competence of the postgraduate residents trained in pathology in different institutions across India. This results in strong disparities in the clinical diagnostic skills, teaching skills, research capabilities and the managerial skills of the graduates. The end users of this training, namely the community, clinicians and health care institutions would benefit from a more uniform and better trained pathologist.

DISCUSSION: There is a wide variation in the way different institutions select students for postgraduate training. The matriculating candidate may have various reasons for joining the field of pathology and the desire and aptitude may play only a minor role in the decision. The institutions are varied in terms of faculty, laboratory support, infrastructure facilities, and evaluation standards, quality control of the laboratories and the program and the institutional support. The products coming out of these programs are thus trained in a variety of fashions and may have varied capabilities to deliver the expectations from a competent pathologist. Some of these factors may be out of the control of individual faculty or the heads of departments in pathology. This article explores the various options available and provides some guidelines for those who want to pursue this path. 


\section{THE CURRENT SCENARIO:}

Admissions: There may be students who opt for pathology as a last resort because they could not get into any other clinical program. Female students who are married usually opt for this subject with a misconception that they can relax in the department and look after their children. Such students may not be motivated to actively learn and enjoy the practice of pathology.

Learning Objectives and Competences: Very few departments if any have written learning objectives or outcome objectives for their postgraduate program. The trainee is not very clear about his objectives and what is expected out of him. Most of the learning is HOD (Head of the department) centric. Majority of the postgraduates trained have accumulation of theoretical knowledge with little practical competences.

Curriculum: The Medical Council of India and Universities provide a defined curriculum to the departments but the practice is only on paper. According to the standard curriculum postgraduates have to be equally trained in skills and academics with proper application. In Government Medical Colleges the curriculum may be restricted to what the local faculty knows or feel is important.

Teaching Methods and Techniques: A post graduate student should be well versed with all branches of pathology, but to his misfortune during the training period much emphasis is made on surgical pathology especially tumor pathology. Most of the Government Institutes there is very superficial training in clinical pathology. The sad truth is that very few pathologists get the opportunity to practice surgical pathology in any meaningful way after they qualify, the main bread and butter is clinical pathology. There are no well-defined standardized protocols for grossing and reporting in most of the departments leading to non-uniform learning among students.

In most of the Government Institutes medical autopsies are no longer performed. The autopsies are one of the best resources in the training of a pathologist. Very few institutions involve the postgraduate students actively and constructively in the teaching of undergraduate medical students; usually they are restricted to the practical sessions. Opportunities for research and publication, exposure to molecular techniques, knowledge of business practices in pathology, awareness of legal practices and career counseling is very much lacking in most of the teaching methods.

Evaluation Methods: As per the Medical Council of India the postgraduates have to be assessed periodically in relevance with acquiring communicative skills, approach towards the patient and the families, professional behavior, competence in subspecialties, skills in interpreting reports and arriving at diagnosis, managerial skills and participating in continued medical education programmes. All the mentioned skills have to be individually evaluated and recorded. Many institutions rarely follow the guidelines effectively.

Defined Career Tracks in Branches of Laboratory Medicine: Lack of counseling on choosing a career path following the completion of training is a malady not just confined to India but affects even other accomplished nations. Majority of the neophyte pathologists are dogged by 'after-residencywhat' syndrome. It is vital for one to form a strategy in order to be reasonably successful in life after MD training. Unfortunately, since most residents and youngsters have not organized their thoughts 
and commence the job search without a concrete strategy or plan there is often great confusion, frustration and confoundment. Many bright prospects find themselves at the crossroads and in a dilemma about the future and feel pessimistic about pathology-the subject itself.

METHODS TO IMPROVE: The various observations and suggestions of eminent pathologists and clinicians in this field were as follows.[1,2,3,4,5,6,7,8,9]

1. Providing a list of learning objectives as per Medical Council of India/Universities in a sequential manner and evaluating their achievement in a stepwise process.

2. Hands on training: The trainee should be involved in supervised participation in all the diagnostic and interactive activities of the pathology laboratory.

3. Interaction with patients: The trainee should have supervised interaction with patients. Communication skills need to be taught, practiced and evaluated.

4. Ward rounds (clinical exposure): This will provide an insight to the trainees on what questions the clinicians expect answered in the pathology report.

5. Discussion on the quality of pathology reports: The faculty should provide examples of incomplete, inaccurate, inappropriate laboratory reports and hold discussions with the residents on the construction of good quality reports.

6. Sensitization to applications of molecular pathology and genomics: An attempt could at least be made to discuss the basis for the techniques and the common diagnostic and therapeutic applications of the common ones. If there is a regional laboratory that performs these tests, the trainees should be encouraged to go and observe them.

7. Research methodology and statistical analysis: They should be taught and tested as modules.

8. Exposure to experimental medicine/pathology laboratories: Most departments do not have the facilities for animal experimentation or tissue cultures. An attempt should be made to arrange visitation by trainees to centers where these are available to get a concept on how they run.

9. Clinical correlations: Many pathologists feel that writing a good report is the total activity of a pathologist. The trainees should be encouraged to think about the patient and develop the competence to build a clinical story based on a pathology image and vice versa. This should be a part of teaching and testing.

10. Electronic portfolio (e-portfolio): The trainees should be encouraged to develop an eportfolio of their learning activities. They should add to it and enhance it regularly. The eportfolio could be one vital segment of the overall evaluation of the trainee.

11. Developing algorithms for approach towards diagnosis: The algorithms can be computerized. This is more helpful than jumping to diagnostic conclusions.

12. The evaluations should be in multiple stages, at the end of first three months, first 6,12,18 and 24 months. A greater value should be attached to the in-course evaluation to reduce the tensions and subjectivity of an all or none final examination. The in- course assessment should monitor the communications skills and professional behavior in addition to cognitive skills. The faculty members should also be evaluated by the trainees regularly and should have regular meetings with the residents to discuss and resolve issues related to training. 


\section{REVIEW ARTICLE}

13. Professional behavior like coming to work on time, wearing the appropriate attire to work, compassionate attitude to patients, patient's relatives and colleagues, respect to peer and faculty, showing restraint when angry or provoked, handling professional disagreements without ill-feeling, actively listening to another's opinion, clear and concise speech at biopsy rounds, CPCs, responding accurately, briefly and politely to any queries, showing care for the laboratory area, instruments, slides, specimens, copies of reports, maintaining confidentiality, team-player spirit, leadership qualities, volunteering for community service, etc should be periodically evaluated with appropriate grades.

14. A curriculum model needs to be developed for training the students on the issues involved in setting up a private laboratories and how to handle them. Legal aspects of the practices of pathology also need to be introduced.

15. There needs to be a formal body charged with the oversight of the postgraduate training program in pathology across the country. It could set the curriculum, the standards of education and evaluation in addition to the quality control of the laboratories that are involved in this educational process. It could have a regional branch each for North, South, East and West or pass the charge to the state chapters of the IAPM, towards voluntarily establishing such a body and write the constitution and remit of this committee. Every meeting of the Annual Conference of IAPM Conference (APCON) should have at least one day dedicated to the meeting along with faculty involved in the training programs and representatives from the postgraduate residents. The committee could deliberate electronically on a monthly basis and the news and developments transmitted through an electronic newsletter on the website dedicated for pathology postgraduate training.

Jaiman $S$ et al[10] in order to help a resident in objectively analyzing a career choice and organizing his/her thoughts he had compiled a series of 14 questions. The important factors considered are specialty priority, family, personal financial requirements, location, working conditions etc. Each question can be answered in five different ways. In order to assign more objectivity to the questionnaire he had allotted a score of 1 to 5 for each response [Table 1]. Response point allocation is in ascending order: A has 1 point, B 2, C 3, D 4 and E has 5. Total score ranges from 14 to 70 . Based on the score one can attempt at objectively define a future career strategy. [Table 2].

Suggestions at our Level: The following methods adopted would contribute to improved training in postgraduate curriculum which can be easily adopted by the Medical colleges:

1. Counselling before opting pathology as a postgraduate subject with special emphasis on the scope, extent and future especially in Government Medical Colleges.

2. In the $1^{\text {st }}$ year of Post-Graduation: A well-defined curriculum designed by the head of the department of pathology. Hands on training on basic skills of histopathology, hematology and cytopathology by the senior faculty members of the department. Introduction to grossing and reporting as per standard protocols. Periodic evaluation of the skills, preferably every three months. Stress on professional behavior, communicative skills with evaluation.

3. In the $2^{\text {nd }}$ year of Post-Graduation: Sensitisation to application of molecular pathology, genomics, research modalities and exposure to experimental medicine by collaborating with respective institutes or laboratories. 
4. In the $3^{\text {rd }}$ year of Post-Graduation: Training students in developing algorithm to arrive at diagnostic conclusion and evaluate themselves formatively. Introduction to legal aspects in practice and business practices in pathology. Guiding the students in making a career choice.

\section{REFERENCES:}

1. Zaino RJ, Abendroth CS. Preparing residents for practice: An opportunity to teach professionalism and communication skills as well as diagnostic criteria. Hum Pathol 2010; 41: 923-6.

2. Talbert ML, Dun ST, Hunt J, Hilyard DR, Mirza I, Nowak JA, et al. Competency-based education for the molecular genetic pathology fellow: A report of the association of molecular pathology training and education committee. J Mol Diagn 2009; 11: 497-507.

3. Haspel RL, Arnout R, Briere L, Kantarci S, Marchand K, Tonellato P, et al. A call to action: Training pathology residents in genomics and personalized medicine. Am J Clin Pathol 2010; 133: 832-4.

4. Luning Prak ET, Young DS, Kamoun M, Nachamkin I, Alexander CB, Spitanik SL. 2008 ACLPS panel discussion on resident education in clinical pathology. Am J Clin Pathol 2009; 131: 61822.

5. Smith BR, Wells A, Alexander CB, Bovill E, Campbell E, Dasgupta A, et al. Curriculum content and evaluation of resident competency in clinical pathology (laboratory medicine): A proposal. Clin Chem 2006; 52: 917-49.

6. Yu GH. Goals and guidelines for residency training in cytopathology. Diag Cytopathol 2011; 39: 455-60.

7. Alexander CB. Assessing resident competency in laboratory medicine. Clin Lab Med 2007; 27: 269-81.

8. Roth CS, Watson KV, Harris IB. A communication assessment and skill building exercise (CASE) for first year residents. Acad Med 2002; 77: 746-7.

9. Otte KK, Zehe SC, Wood AJ, Hernandez JS, Karon BS. Legal aspects of laboratory medicine and pathology for residents and fellows: A curriculum for pathology training programs. Arch Pathol Lab Med 2010; 134: 1029-32.

10. Jaiman S. Objective career planning for a resident pathologist. Indian J Pathol Microbiol 2009; 52: 580-2.

\begin{tabular}{|c|l|}
\hline \multicolumn{2}{|c|}{ QUESTIONARE BY JAIMAN S[10] FOR CAREER PLANNING } \\
\hline $\begin{array}{l}\text { I. In What specialty would } \\
\text { one like to establish } \\
\text { one's practice? }\end{array}$ & $\begin{array}{l}\text { A. Only histopathology, cytopathology, hematology. B. Only } \\
\text { histopathology, cytopathology, hematology plus clinical pathology. } \\
\text { C. Clinical pathology and occasional histopathology cytopathology } \\
\text { and hematology. D. Only clinical pathology. E. Does not matter. }\end{array}$ \\
\hline $\begin{array}{l}\text { II. How does one wish to } \\
\text { practice pathology? }\end{array}$ & $\begin{array}{l}\text { A.As a government hospital employee. B.A s a corporate hospital } \\
\text { employee. C. As an employee of a large corporate laboratory. D. As } \\
\text { a part-timer. E. As an individual, entrepreneur }\end{array}$ \\
\hline $\begin{array}{l}\text { III. What kind of financial } \\
\text { compensation does one } \\
\text { expect? }\end{array}$ & $\begin{array}{l}\text { A. Income guarantee. B. Monthly fixed salary with maybe annual } \\
\text { bonus. C. Monthly fixed salary with maybe production incentive. D. } \\
\text { Hourly compensation. E. Willing to risk compensation. }\end{array}$ \\
\hline
\end{tabular}




\section{REVIEW ARTICLE}

IV. How does one relate to working as a junior colleague?

V. What is the most important consideration in selecting the professional practice setting?

VI. How important is spouse's job?

VII. What type of schooling would one prefer for one's children?

VIII. Where should one locate one's practice?

IX. Where would one prefer to live?

X. How does one relate to the administrative and financial aspects pertaining to a laboratory?

XI. How are one's communication skills?

XII. How skilful is one socially?

XIII. How strong are one's personal finances?

XIV. How cautious is one temperamentally?
A. Does not matter at all. B. Not critical as long as there is some leeway. C. Matters and would prefer greater freedom. D. Matters but little cautious and restrained by compulsions. E. Cannot work as a junior colleague.

A. Only academic professional environment B. Academic plus geographical location. C. Financial compensation plus geographical location. D. Only financial compensation. E. Does not matter.

A. Extremely essential. B. Essential. C. Very important but not essential. D. Important. E. Not important.

A. A government school (kendriya vidyalaya) B. A reputed private school. C. Any local reasonably good school. D. Only a school of social standing. E. Not only a school with a social standing but also the most expensive school.

A. Does not matter. B. In an urban setting. C. Urban or suburban setting. D. Urban, suburban or rural setting. E. Commercially viable setting.

A. Does not matter. B. In an urban setting. C. Urban or suburban setting. D. Urban, suburban or rural setting. E. Preferably close to a commercial setting.

A. Not interested. B. Participate occasionally but unwilling. C. Participate willingly. D. Interested. E. Very interested and passionate.

A. Generally Poor .B. Manageable. C. Circumstantial D. Good. E. Excellent generally

A. Generally Poor. B. Manageable. C. Circumstantial D. Good. E. Excellent generally

A. Average. B. More than average. C. Good. D. Quite good. E. Excellent.

A. Extremely cautious. B. Cautious. C. Cautious but not averse to risk-taking. D. Can take risks. E. Greater the risk greater the motivation.

Table 1

Score: A-1, B-2, C-3, D-4, E-5.

\begin{tabular}{|c|l|}
\hline SCORE 14-28 & $\begin{array}{l}\text { May fare better if resident plans for a government establishment and } \\
\text { practice anyone of the speciality: histopathology, cytopathology and } \\
\text { hematology }\end{array}$ \\
\hline SCORE 29-42 & May fare better if resident plans for a corporate hospital practice \\
\hline SCORE 43-56 & May fare better if resident plans to work for a laboratory \\
\hline
\end{tabular}




\section{REVIEW ARTICLE}

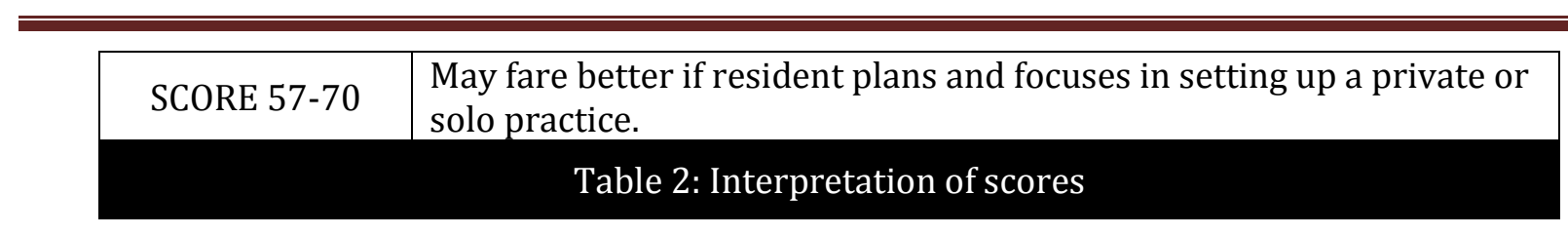

\section{AUTHORS: \\ 1. Prasad Uma \\ PARTICULARS OF CONTRIBUTORS: \\ 1. Associate Professor, Department of Pathology, RIMS, Srikakulam, Andhra Pradesh.}

FINANCIAL OR OTHER COMPETING INTERESTS: None

\section{NAME ADDRESS EMAIL ID OF THE}

\section{CORRESPONDING AUTHOR:}

Dr. Prasad Uma,

Q. No. 49-3-3,

Lalithanagar,

Visakhapatnam-530016,

Andhra Pradesh.

E-mail: usha1966411@gmail.com

Date of Submission: 20/04/2015.

Date of Peer Review: 21/04/2015.

Date of Acceptance: 08/05/2015.

Date of Publishing: 18/05/2015. 